OPEN ACCESS

Edited by:

Hang Xiong,

Huazhong Agricultural University,

China

Reviewed by:

Henry Michael Kim,

York University, Canada

Francesco Santini,

University of Perugia, Italy

*Correspondence:

Mireille van Hilten mireille.vanhilten@wur.n

Specialty section:

This article was submitted to Non-Financial Blockchain, a section of the journal

Frontiers in Blockchain

Received: 29 May 2020

Accepted: 31 August 2020 Published: 30 September 2020

Citation:

van Hilten $M$, Ongena $G$ and Ravesteijn P (2020) Blockchain for Organic Food Traceability: Case Studies on Drivers and Challenges.

Front. Blockchain 3:567175. doi: 10.3389/fbloc.2020.567175

\section{Blockchain for Organic Food Traceability: Case Studies on Drivers and Challenges}

\author{
Mireille van Hilten ${ }^{1 *}$, Guido Ongena ${ }^{2}$ and Pascal Ravesteijn ${ }^{2}$ \\ ${ }^{1}$ Wageningen Research, Wageningen Economic Research, Wageningen, Netherlands, ${ }^{2}$ Utrecht University of Applied \\ Sciences, Utrecht, Netherlands
}

Purpose: This article evaluates the application of blockchain technology to improve organic or fair-trade food traceability from "Farm to Fork" in light of European regulations. This study aims to shed light on the challenges in the organic food chain to overcome, the drivers for blockchain technology, and the challenges in current projects.

Design/Methodology/Approach: For this research, a case study approach was taken in which four blockchain projects were evaluated on their success.

Findings: Organic food supply chain companies aiming to improve food traceability with blockchain face two key decisions, depending on the characteristics of the organic value chain, regarding (1) optimizing chain partner collaboration and (2) the selection of which data to capture in the blockchain. Other challenges were data confidentiality, validation of data inputs, and interoperability. Easy verification of certification data, accountability, improved risk management, insight into trade transactions, simplified data collection and exchange, and improved communication account for the benefits. Regardless of what drives companies toward whole-chain traceability, for example, customer satisfaction, it does not necessarily require blockchain technology. Blockchain does enable faster food traceability, which is expected to be more applicable to a complex food supply chain.

Research limitations/Implications: The limitations of this study are represented mainly by the scarcity of organic blockchain projects aiming to minimize pesticide inputs and limited availability of information of commercial projects.

Practical Implications: This study shows that blockchain is currently successfully being implemented on a small scale to create whole-chain traceability of organic and fair-trade food.

Originality/Value: This research addresses the intersection of food supply chain and organic food quality and certification. The focus on origin information and importance of organic data elements may underpin other research on European Union regulations in relation to food traceability, adding value to the body of knowledge on the current status of blockchain technology.

Keywords: traceability, blockchain, organic, agri-food, food supply chain, interoperability, certifications, fair trade 


\section{INTRODUCTION}

Consumers, who buy organic food, have expectations about its quality and rely on certifying organizations to verify this quality as well as to provide information about the origin of organic products. However, organic food traceability knows several issues, such as problems with organic labeling, certification fraud, and concerns about transparency of food information.

The international food supply chain is currently under pressure to provide information about environmental impact, food fraud, quality, and safety (Langelaan et al., 2013). Several food crises occurring over the last decades have increased consumer demand for high-quality food and easy access to food information (Schleenbecker and Hamm, 2013). Additionally, food travels increasingly large distances from producer to consumer ("Farm to Fork") because of globalization in the food eco system (Lehtinen, 2017). Information about the origin of food is especially important in the organic food supply chain, because it can indicate the use of pesticides, genetically modified organisms (GMOs), fair payment, and the environmental or carbon footprint. Pesticides could be toxic to humans and can have acute and chronic health effects. These health effects and the effects on the environment by the exposure to pesticides are a continuing concern, according to the World Health Organization (WHO, 2018). If it turns out an organic product is actually not organic, the consequences for supply chain partners could be severe. For example, following a mushroom scandal involving a supermarket giant in the Netherlands, retraction of the main organic certificate (provided by Skal-the Dutch certifying organization for organic products) led to the liquidation of the local mushroom grower. Europe-wide data on pesticides in organic food made available by the European Food Safety Authority (EFSA) for the first time in 2007 show that organic food can indeed contain pesticides (Euractiv, 2009). Although samples of organic food generally did not exceed maximum levels as much as samples of conventionally grown food, pesticide residues were found in those samples too. Since then, annual research shows legal levels were exceeded in $4.1 \%$ of samples of conventional food and $1.5 \%$ (vs. $1.3 \%$ in 2016) of the organic samples analyzed. Although EFSA concluded that "acute and chronic dietary exposure to pesticide residues is unlikely to pose concerns for consumer health" (EFSA, 2017), it can well be that certified organic food could contain pesticides. Perhaps propelled by these scandals, consumers are increasingly becoming concerned about the source of their food and beverages (Bitcoin Magazine, 2017). In summary, the above examples illustrate the accrued need for traceability in the food supply chain.

Prior research stipulates the promising blockchain characteristics of, among others, transparency (Atzori, 2015; Underwood, 2016), avoiding fraud and manipulation (Cai and Zhu, 2016), and increased control (Kraft, 2016) and access to information (Swan, 2015). These characteristics advocate traceability. This thus suggests that blockchain has a potential to achieve higher levels of traceability.

Blockchain technology draws much attention as a possible disruptor in various industries. The World Economic Forum (WEF, 2015) considers blockchain to be among six computing "mega-trends" that are likely to shape the world in the next decade. Blockchain seems successfully implemented in a few cases (Kshetri, 2018), yet most studies describe the use of blockchain from a technical design point of view in which new supply chain models are proposed (Zhang et al., 2013; Ji and Tan, 2017; Casado-Vara et al., 2018), or the practicality of such studies is limited to a pilot or testing scenario (Bhatt and Zhang, 2013). So far, blockchain research in the field of food traceability lacks specifics about actual implementation of blockchain solutions in business to prove their success (Galvez et al., 2018). A proof-of-concept study evaluated blockchain technology in the organic food sector, but recommends future research to use cases where food integrity and inclusive development are key themes (Ge et al., 2017). However, this study has not established if blockchain has been successfully implemented by organizations in the food supply chain to improve organic food traceability.

In light of the above observations, the key objective of this study is to illustrate blockchain's possibilities for food traceability in the organic food supply chain. This study therefore offers the promise of filling pivotal gaps in the few studies on blockchain deployment in the food supply chain with a focus on traceability in the organic context. To fill these gaps, this research evaluates the role that blockchain plays in the improvement of organic traceability by analyzing four real-world blockchain projects in a multiple-case study. The key outcomes show that blockchain can improve organic food traceability, as demonstrated by two of the four use cases that improve whole-chain traceability. At the same time, one of the use cases showed that applying blockchain technology is not the only way to improve organic food traceability. Blockchain can improve food traceability in the organic food supply chain if "chain discovery" and "data capture" are aligned with the characteristics of the organic value chain.

The remainder of this article is structured as follows: we proceed by first providing a literature review of traceability systems, types of organic food traceability, and previous work in this field. Next, we discuss the research method employed in this study, where we provide brief descriptions of the selected cases. Subsequently, the cases are presented in Results of Use Case Analysis. This is followed by a section on discussion and implications. The final section provides concluding comments.

\section{THEORETICAL BACKGROUND}

To help understand how blockchain could influence food traceability, the literature provides several main concepts. First, a traceability system is decomposed into core entities (Moe, 1998) to which we can relate different types of traceability. Second, the concept of tracking and tracing is essential for whole-chain traceability and is also described (Opara, 2003). To fully understand traceability systems within the supply chain sector, research by Aung and Chang (2014) describes the food traceability system. These concepts are translated to the organic food supply chain. Finally, blockchain is described from the technology perspective and in relation to the organic food chain. 


\section{Traceability Systems}

Moe (1998) pictured the fundamental structure of a traceability system, as depicted in Figure 1. A set of core entities representing products and activities provided by Kim et al. (1995) was extended with descriptors essential to secure ideal traceability. By selecting the number and content of subdescriptors, the scope of a traceability system is put in place (Moe, 1998).

Opara (2003) considers traceability specifically for agriculture, which is regarded as a part of the overall quality management system that "adds value by providing the communication linkage for identifying, verifying and isolating sources of noncompliance to agreed standards and consumer expectations." In the context of this research, this concerns the identification and verification of organic food, as well as the instances in which organic food does not meet organic certification or standards once consumers buy it. By adding this dimension, the fundamental structure (Moe, 1998) is expanded to a traceability system that allows for traceback to the producer and trace-forward to individual consumers and acts like a prevention system (Opara, 2003).

Traceability in itself and related terms such as traceable resource unit (TRU) and the components of a traceability system are also described (Opara, 2003; Olsen and Borit, 2018). A TRU is a unit with unique characteristics from the point of view of traceability (Kim et al., 1995) and can be used to determine the granularity to which products are traced. Oneto-many relationships between traceability codes and TRUs are very common in the food supply chain because of product conversions, although one-to-one relationships allow for a more powerful traceability system. This is why Olsen and Borit (2018) considered these to be the main components of a traceability system and the respective implementation options.

Aung and Chang (2014) provided an overview of the food supply chain, including transport and information flows through the traceability system (Figure 2). Their framework clearly indicates the difference between internal traceability within an organization and external traceability between supply chain partners, in order to obtain "whole supply chain traceability" (Aung and Chang, 2014). The model also positions regulations and quality assurance systems alongside the core processes of the food traceability information system.

Lindvall and Sandahl (1996) use similar types of traceability from a software development standpoint (vertical and horizontal traceability). Wognum et al. (2011) use these exact same terms as dimensions to describe the difference between traceability requirements coming from legislation (vertical) and information sharing (horizontal), illustrating the various ways of interpreting traceability.

\section{Organic Food Traceability: Types and Issues}

Organic food certification is based on European regulations that formally assign inspection organizations for each European country (European Commission, 2018) that certify each supply chain partner on a yearly basis. Although the definition of "organic" could include sustainability together with agro-ecology and protecting living organisms (Verhoog et al., 2007), organic production does not need to represent the full list of ethical considerations (Browne et al., 2000). Verhoog et al. (2007) call this the "no-chemical approach" that does not permit materials or techniques such as synthetic pesticides, inorganic fertilizers, and GMOs, often leading to the conversion process from conventional to organic farming. For the purpose of this research, the definitions of organic are all considered relevant, yet the research focus is specifically placed on the no-chemical approach. Although fair-trade certification could overlap organic certification, in this research it is considered to be a different approach that focuses on fair working conditions, such as pricing and payment. Many other sustainable food certification schemes exist, such as the Rain Forest Alliance that encompasses the pillars social, economic, and environmental of sustainability, including biodiversity and improved livelihoods (Rainforest Alliance, n.d.).

The difference between internal and external traceability in Traceability Systems is relevant for traceability in the organic food chain, because organic certification is registered at several levels, from certification of a production process to sampling of an individual product. Differences between concepts and these levels of granularity (the level at which a unit or TRU is traced) to which traceability solutions need to be adapted (container, batch, single product) were identified in the literature (Table 1). For example, logistic tracing and origin tracing are two different concepts, although not mutually exclusive as both logistics and origin can be tracked at the same time.

Issues that were found in the literature around wholechain traceability of organic food are (1) organic labeling (Aung and Chang, 2014), (2) third-party certification (TPC) fraud (Munteanu, 2015; Ge et al., 2017), (3) transparency issues (Kshetri, 2018), (4) the absence of European Union (EU) legal requirements for data elements to describe organic origin (Charlebois et al., 2014), and (5) interoperability (Mainetti et al., 2013).

Besides the many different organic labels used in Europe (Lehtinen, 2017), also mislabeling of organic food (Giannakas, 2002) and poor consumer knowledge (Janssen and Hamm, 2012) are issues in organic food traceability. First, organic trade is built on trust among chain partners in the system of certification and in the certification and inspection bodies performing their duties (Munteanu, 2015). Up and until the selling point to the consumer, all chain partners handling the organic produce must be certified. Muntenau's review of literature (2015) on the role of the TPC system in Europe shows there is room for improvement, of which the requirement for confidentiality, guaranteed by law, ensures that information managed by operators cannot be published (Cuéllar-Padilla and Ganuza-Fernandez, 2018). Second, because the growing certification market in the EU presents problems for inexperienced stakeholders, fraud may occur (Ge et al., 2017). Third, Article 18 of the General Food Law (178/2002) does not state any requirements for internal traceability (Charlebois et al., 2014). Although regulations indicate which records need to be kept at the internal level for an individual chain partner or "operator," it is not required to share any information between chain partners to obtain organic certification. Also, it can be difficult to share information to obtain whole-chain traceability, because using different 


\section{Core entities Essential descriptors Sub-descriptors}

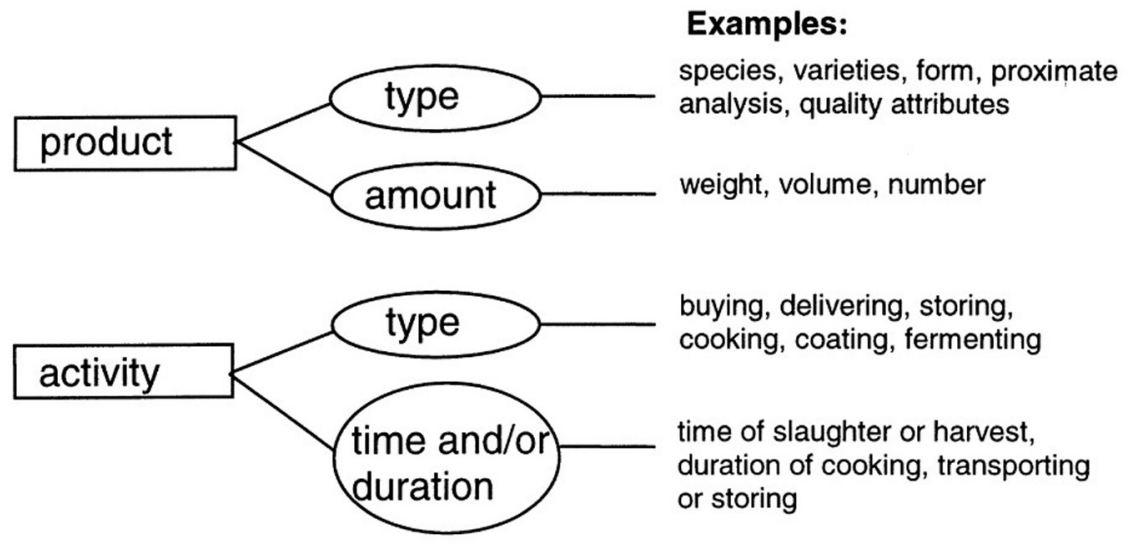

FIGURE 1 | Fundamental structure of a traceability system. Reprinted from "Perspectives on Traceability in Food Manufacture," by Moe, 1998, Trends in Food Science and Technology, 9(5), 211-214. Copyright 1998 by Elsevier Science Ltd. Reprinted with permission.

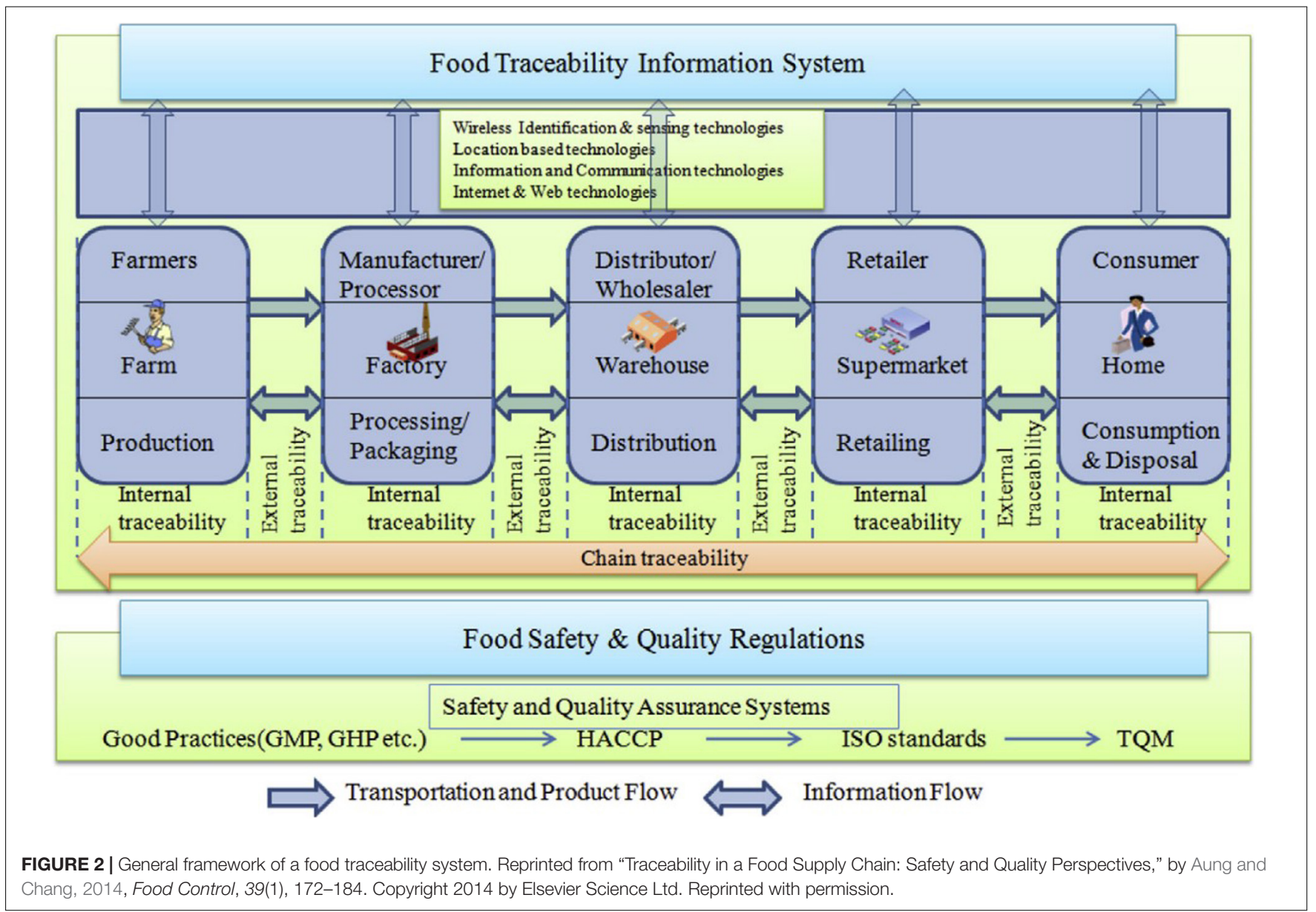


TABLE 1 | Organic traceability types, adapted from Moe (1998), Kim et al. (1995), and Bhatt et al. (2013).

\begin{tabular}{|c|c|c|}
\hline & $\begin{array}{l}\text { Internal traceability (Moe, } \\
\text { 1998) Vertical (Lindvall and } \\
\text { Sandahl, 1996) }\end{array}$ & $\begin{array}{l}\text { External traceability (Moe, } \\
\text { 1998) Horizontal (Lindvall } \\
\text { and Sandahl, 1996) }\end{array}$ \\
\hline $\begin{array}{l}\text { Core entity (Kim } \\
\text { et al., 1995) }\end{array}$ & Inputs matched to outputs & $\begin{array}{l}\text { Activity (process): location and } \\
\text { movement tracking Product } \\
\text { (identification throughout chain) } \\
\text { (Bhatt et al., 2013) }\end{array}$ \\
\hline Tracing objective & Logistics & $\begin{array}{l}\text { Origin verification Provenance } \\
\text { verification }\end{array}$ \\
\hline $\begin{array}{l}\text { Granularity (TRU } \\
\text { level) }\end{array}$ & $\begin{array}{l}\text { Pallet, bag, container, truck, } \\
\text { train, ship, process }\end{array}$ & Single piece, batch \\
\hline Organic certification & Certification validity & $\begin{array}{l}\text { Product/farm (origin) data } \\
\text { elements }\end{array}$ \\
\hline
\end{tabular}

data models will cause interoperability issues between systems (Mainetti et al., 2013).

\section{Blockchain Application in the Agri-Food Supply Chain}

Blockchain technology was invented by Nakamoto (2009) and became known to the main public through the peer-to-peer Bitcoin cryptocurrency application. This distributed ledger technology is characterized as being immutable and transparent, providing solutions that are secure, rapid, and trustworthy. Transactions that are stored "on a blockchain" are seen as records in a block. The block also contains a time stamp and a hash, which connects it to a previous block, forming a chain of blocks that cannot be altered.

The distributed ledger technology is characterized by its decentralized, peer-to-peer architectural approach for the network scheme (Karthika and Jaganathan, 2019). Where a centralized network also implies one organization or entity to govern the network, also referred to as a central node of control, a blockchain is a chain of blocks for all transactions in the network, making it a distributed and shared database (Mistry et al., 2020). To create new blocks, various ways of verification can be used in such a distributed network, based on a blockchain protocol (Bitcoin, Ethereum, Hyperledger, and many more). This is called a consensus mechanism and is based on a computer algorithm. Consensus is seen as the core of blockchain, such as proof of work and proof of stake to confirm the reliability of a recorded transaction (Adolph et al., 2018).

Several blockchain types indicate how access is controlled and how the data are managed. Managing the access to data is described as the concept of authentication, which is public vs. private. Authorization is the concept of managing permissions to the data; hence, there are permissioned and permissionless blockchain solutions (Mistry et al., 2020). Blockchain technology is further summarized by Karthika and Jaganathan (2019) as being immutable, transparent, available, consistent, and enabling privacy achieved through anonymity.

When adding smart contracts to a blockchain solution, it becomes possible to implement and execute business processes across organization boundaries, also when the trusted third party, reviewing all critical transaction communications between two parties who both trust the third party, is not agreed upon (Mendling et al., 2018). A smart contract can be seen as a digitized business arrangement, which can be triggered automatically when certain criteria are met to validate and verify chain partners (Mistry et al., 2020). The changing role of the middleman, for example, a notary or a certification body, often comes into play when blockchain and smart contracts are discussed. Kim and Laskowski (2018) made a case for the contribution of traceability ontologies to blockchain design, analyzed it, and translated this to smart contracts. This made provenance traceability possible on the Ethereum blockchain platform (Kim and Laskowski, 2018). There is no need for third-party intermediaries with blockchain technology in order to verify or transfer ownership (Dobrovnik et al., 2018); therefore, the role of certifying organizations in the organic food traceability process could change, possibly minimizing fraud.

The potential applications of blockchain technology across a range of industries from financial, industrial, to social have been of great interest to companies and research institutes (Ge et al., 2017). Although blockchain technology itself has been researched frequently lately, a study comparing eight blockchain projects affirmed that blockchain application in the food supply chain is still rare, and information about technical implementation is not detailed (Galvez et al., 2018). Exploring four use cases, the high level of collaboration and commitment necessary to adopt blockchain technology was seen as a barrier (Hackius and Petersen, 2017).

To improve information management of agri-food transactions, blockchain was found to be of great relevance in the agri-food sector in the Netherlands (Ge et al., 2017). Wolfert et al. (2018) position blockchain as a core technology within the "cyber-physical management cycle of agricultural food production" with other technologies such as the Internet of Things (IoT), big data analytics, and artificial intelligence. In this cycle, public decision making can rely on the concept of smart farming that monitors, analyzes, and controls farming (Wolfert et al., 2018).

A study on the Indian organic food market, using analytic hierarchy process analysis, found that blockchain is superior to other technologies [supply chain with limited technology, social media, radiofrequency identification (RFID), enterprise resource planning (ERP), and IoT combined with RFID]. A network built on blockchain technology ensures fair-trading and a circular economy, and blockchain can play an important role in supporting farmers to improve the food quality in the supply chain. The proposed model, however, is quite theoretical, and the authors find that more research is required before implementing it in the field (Balakrishna Reddy and Ratna Kumar, 2020). A study by Zhao et al. (2019) showed that several researchers proposed different traceability systems in this context based on blockchain, combined with other technologies (such as RFID, IoT, NFC, cloud computing, and big data) across different agri-food value chains. It was found that most of the traceability systems proposed did not move beyond the conceptual phase and provided for little empirical research to indicate applicable to the reality of 
agri-food chains (Zhao et al., 2019). In relation to the organic food traceability criteria, immutability and decentralization of data using blockchain have the most impact on alleviating issues concerning certification fraud, transparency throughout the supply chain, and the use of common data elements.

\section{RESEARCH METHODOLOGY}

The research followed a multiple-case study method based on data collection through interviews and public project documentation. This section describes the reasoning for the multiple-case study, the case selection, the four selected cases, the sources of the data, and the analysis of the data.

\section{Multiple-Case Study}

Yin (2018) and other scholars regard the case study method as a way to investigate a contemporary phenomenon within its real life context (Benbasat et al., 1987; Eisenhardt, 1989; Yin, 2018). This research follows a multiple-case study method, because it allows for a study of cases in their unique context within the European organic food supply chain and the effect of the blockchain phenomena on the role of the intermediaries, in this case certification bodies. A multiple-case study allows for the exploration of the differences and commonalities across cases so that researchers can predict similar results across cases.

\section{External Validity}

The cases were expected to show similar results because of their focus on origin traceability (organic and fair trade), which is literal replication (Benbasat et al., 1987; Yin, 2018). Both organic and fair-trade cases, and both smaller and larger chains, are selected to make the results generalizable beyond this study. For example, one large retailer will not be considerably different in the way it operates the food supply chain from another large retailer.

\section{Internal Validity}

Because EU law regulates traceability requirements, traceability data from cases were analyzed to identify data elements necessary for organic food traceability. Data triangulation was performed using multiple sources of evidence (interviews, desk research, and case documents) to ensure validity of the constructs. Pattern matching across cases and explanation building using documented findings in both Atlas.ti and a collection of reports and notes ensured internal validity (Yin, 2018). In addition, logic models from literature were the basis for evaluating the cases.

\section{Reliability}

Concepts from the literature were used to evaluate the cases. For example, different types of traceability and traceability issues were used as a topic list for one semistructured interview (in Dutch) per case, allowing for structured data analysis and evaluation of the cases. People in business or information technology roles were interviewed to ensure the capture of necessary details concerning technical information and product traceability. Rigorous documentation allows for repeatability of the case study.

\section{Selected Cases}

A total number of 34 cases were found across industries by searching the literature and the internet for blockchain projects, including nonorganic and cases outside of Europe. Five cases were selected from a list of 11 organic and fair-trade projects by using the criteria of being either in flight, well documented, or having the availability to interview a project representative. Allowing fair-trade cases ensured meeting a minimum of five cases and covered the risk of contacts not being available for interviews. Four blockchain projects were available and evaluated individually by triangulation of multiple document types, interviews, and demonstration of the solution (where possible). Each case of a multiple-case study design is carefully selected so that it will show similar or different results (Yin, 2018). This research includes both projects that ended, meaning the blockchain solution was not developed or operationalized, as well as projects that were successful, so that any similar considerations for not using blockchain for food traceability can be uncovered.

\section{Case Descriptions}

The details of the four studied companies are discussed below, and the description of the selected cases is also summarized in Table 2. The first case studied was Fairfood (No. 1), which created an open-source, public blockchain solution to trace fair trade and organic nutmeg from its origin to the consumer. The solution provides traceability for multiple stakeholders, such as Verstegen spices, who sells the nutmeg from Indonesia on the Dutch market (Back to the Origin, 2019). FishTales trades tuna and other fish products selling to European retail and was selected as another use case (No. 2). This blockchain project aimed to trace fairtrade pole and line caught tuna from fishermen to the consumer (Fisheries-Fish Tales, 2019). A private blockchain solution by a large Dutch retailer, remaining anonymous, was studied as a next use case (No. 3). Consumers can scan a quick response code (QR code) on the label of a bottle of juice providing product and traceability information about the Rainforest Alliance-certified

TABLE 2 | Overview of selected cases.

\begin{tabular}{|c|c|c|c|c|}
\hline & No. 1 Fairfood "Back to the origin" & No. 2 FishTales Pole-caught tuna & No. 3 Anonymous & No. 4 Anonymous \\
\hline Food product & Nutmeg (spices) & Tuna (fishery) & Citrus fruit (fruit) & Rice (arable) \\
\hline Chain partner type & NGO & Wholesaler & Retailer & NGO \\
\hline Organic segment & Organic Fair-trade/payment (blockchain wallet) & Fair-trade (line caught) & Rainforest Alliance & Organic Fair-trade \\
\hline Region of product origin & Indonesia & Maldives & South America & Cambodia \\
\hline Project status & Production & Concept phase & Production & Ended \\
\hline
\end{tabular}


TABLE 3 | Case data sources.

\begin{tabular}{|c|c|c|c|c|}
\hline & $\begin{array}{l}\text { No. } 1 \text { Fairfood "Back to the } \\
\text { origin" }\end{array}$ & $\begin{array}{l}\text { No. } 2 \text { FishTales Pole-caught } \\
\text { tuna }\end{array}$ & No. 3 Anonymous & No. 4 Anonymous \\
\hline Role of person interviewed & $\begin{array}{l}\text { Project manager/business } \\
\text { developer }\end{array}$ & Sustainability manager & $\begin{array}{l}\text { Data quality and governance, } \\
\text { project manager }\end{array}$ & Private sector advisor \\
\hline Project documentation & $\begin{array}{l}\text { Blog article (Bolt and Senou, } \\
\text { 2019) Company website: } \\
\text { www.fairfood.nl List of data } \\
\text { elements (fields stored in } \\
\text { blockchain) - not public }\end{array}$ & $\begin{array}{l}\text { Presentation at live Blockchain } \\
\text { event PowerPoint presentation } \\
\text { (van Dijk, 2018) Company } \\
\text { website: www.fishtales.nl List of } \\
\text { data elements (fields stored in } \\
\text { blockchain) - not public }\end{array}$ & $\begin{array}{l}\text { Infographic Project video } \\
\text { Company website }\end{array}$ & $\begin{array}{l}\text { Presentation at live project } \\
\text { event PowerPoint presentation } \\
\text { Company website }\end{array}$ \\
\hline
\end{tabular}

TABLE 4 | Use case evaluation.

\begin{tabular}{|c|c|c|c|c|c|c|c|c|}
\hline Case no. & Industry & To trace & $\begin{array}{l}\text { TRU level } \\
\text { (granularity) }\end{array}$ & Standard(s) & $\begin{array}{l}\text { Standard } \\
\text { compliance }\end{array}$ & $\begin{array}{l}\text { EU law } \\
\text { compliance }\end{array}$ & Traceability drivers & $\begin{array}{l}\text { Blockchain } \\
\text { considerations }\end{array}$ \\
\hline 1 & Spices & $\begin{array}{l}\text { 1: Product } \\
\text { 2: Transaction }\end{array}$ & $\begin{array}{l}\text { Bag, } 50 \text { kg, } \\
\text { Container }\end{array}$ & GS1 & Yes & $\begin{array}{l}\text { Yes (Wholesaler } \\
\text { responsibility) }\end{array}$ & $\begin{array}{l}\text { Complexity (product } \\
\text { conversion) Amounts of data } \\
\text { Product traceback } \\
\text { Transparency Not main driver: } \\
\text { Costs Additional: Speed } \\
\text { Information collection and } \\
\text { sharing Risk management }\end{array}$ & $\begin{array}{l}\text { Governance } \\
\text { Adoption Privacy } \\
\text { Additional: Data } \\
\text { selection } \\
\text { Labor-intensive }\end{array}$ \\
\hline 2 & Fishery & $\begin{array}{l}\text { 1: Product: fish } \\
\text { origin = boat } \\
\text { identification } \\
\text { 2: (Logistic) } \\
\text { process }\end{array}$ & Cage & GS1 & No & $\begin{array}{l}\text { No, but did focus } \\
\text { on local law }\end{array}$ & $\begin{array}{l}\text { Lack of records Product } \\
\text { traceback Transparency Not } \\
\text { main driver: Costs Amounts } \\
\text { of data Paper documents } \\
\text { Additional: Accountability }\end{array}$ & $\begin{array}{l}\text { Adoption } \\
\text { Confidentiality } \\
\text { Validation Not } \\
\text { main issue: } \\
\text { Governance } \\
\text { Privacy Additional: } \\
\text { Labor-intensive }\end{array}$ \\
\hline 3 & Fruit & Product & $\begin{array}{l}\text { Nets, } \\
\text { cooltanks, } \\
\text { blender-tank, } \\
\text { containers }\end{array}$ & GS1 & $\begin{array}{l}\text { Not applicable, } \\
\text { use GS1 by } \\
\text { choice }\end{array}$ & No & $\begin{array}{l}\text { Interoperability (EDI, APIs) } \\
\text { Transparency }\end{array}$ & $\begin{array}{l}\text { Confidentiality Not } \\
\text { main issue: } \\
\text { Governance } \\
\text { Additional: } \\
\text { Scalability } \\
\text { TRU-level }\end{array}$ \\
\hline 4 & Arable & Product & Big bag, batch & Not applicable & No & No & $\begin{array}{l}\text { Costs Product traceback } \\
\text { Transparency Paper documents } \\
\text { Not a main driver: Trust }\end{array}$ & $\begin{array}{l}\text { Confidentiality } \\
\text { privacy/anonymity } \\
\text { validation }\end{array}$ \\
\hline
\end{tabular}

citrus fruit originating from South America. The final case studied (No. 4) was a public blockchain pilot initiated by a nongovernmental organization (NGO), remaining anonymous, tracing organic, fair-trade rice throughout the value chain.

\section{Sources of Data}

Allowing for structured data analysis and evaluation of the cases, data were collected through semistructured interviews and analysis of project documentation.

For all four cases, an interview with a minimum duration of $60 \mathrm{~min}$ was performed. The case representatives were experienced project managers involved in blockchain technology implementation of the selected cases and in the fair trade or organic food industry. Their roles are displayed in Table 3. An interview guide based on a topic list with common traceability issues from the literature was followed. Furthermore, an Excel form was used throughout the research process (before, during, and after the interviews) to note and collect data points for each case. This case data template included the organic food traceability issues found in the literature (Organic Food Traceability: Types and Issues), possible drivers, challenges, and improvements.

Document analysis of each case was performed by reading gray literature about the projects, which was mostly publicly available. The project documentation reviewed was publicized at the time the research was performed: between 2018 and 2019. Table 3 provides an overview of these documents (website, document, video, and PowerPoint).

\section{Analysis of Data}

Open coding was used to give meaning to pieces of text from the transcribed interviews using Atlas.ti quotations to add observations and notes (Smit, 2002). For each case, the interview data were coded on a conceptual level, which implies that text is converted into concepts and then categorized using the initial concepts from the standard case list as the scheme. This also ensured validation of the information that was noted manually during the interviews. Throughout the coding process, 
TABLE 5 | Traceability drivers and challenges.

\begin{tabular}{ll}
\hline Drivers & Challenges \\
\hline Information sharing & Adoption \\
Trust & Granularity \\
Proof & Confidentiality \\
Data collection & Governance \\
Speed & Validation \\
Paper documents & Scalability \\
Accountability & Labor-intensive \\
Lack of records & Privacy \\
Pioneering & Data selection \\
Communication & Adoption \\
\hline
\end{tabular}

relationships between codes and between categories, also called links, were created to code structurally, which is called axial coding (Smit, 2002). Like this, the open coding was put back together in new ways creating connections between categories or the codes (Smit, 2002). Codes were added to new issues around food traceability that were brought forward during use case interviews. Issues during project implementation or reasons to end a blockchain project were also coded and interrelated.

\section{RESULTS OF USE CASE ANALYSIS}

The blockchain cases were analyzed individually in detail resulting in an overview of results, main drivers, and considerations and an overview of the case results in light of the organic traceability issues from Organic Food Traceability: Types and Issues.

\section{Blockchain Projects}

The four projects showed quite different characteristics. Table 4 provides a detailed overview of the 4 use cases. Apart from Cases 1 and 3 where, respectively, products nutmeg and citrus fruit are traced from both an origin and (partly) from a logistic perspective, all projects studied had the primary goal to create traceability throughout the entire chain, from end to end, with transparency for the consumer as the main benefit. Because the objective of the study is to evaluate whole-chain traceability in relation to the origin of the product, projects were not evaluated for ameliorating internal traceability.

Data analysis using Atlas.ti provided information on the frequency or "groundedness" of codes. From this analysis based on axial coding, blockchain drivers and challenges were prioritized (Table 5). Although not found as a driver in the literature, and especially for Cases 1 and 2, information sharing throughout the entire chain was the most important driver. Trust is a key characteristic of blockchain technology and was expected to be the main driver to improve traceability. However, for all cases, chain partners were already collaborating well and had established trust. Only for Case 3 gaining even more trust in the own supply chain played a role. Proof or a guarantee was the next driver for traceability to be able to have proof of certification at the source or the products origin. Data collection is related to information sharing, but was also an independent driver, because blockchain can be a way to gather information that previously was more difficult to obtain. For three cases (Cases 1, 2, and 3), the fact that these data could be used to trace products more quickly is the next driver. To be able to digitize records or transactions and start to move away from paper-based processes was another driver. Accountability for what happens in the supply chain was a driver for blockchain as well. Not having any information in certain steps of the process or that tracing products is currently done by making lots of telephone calls, and sending e-mails was another driver to want to improve traceability with blockchain technology. Finally, being able to pioneer with an emerging technology such as blockchain was a driver in three of the four cases and improving communications in general as well.

Investment costs and return on investment in the long run were important but not seen as main drivers. In one case, providing the right information to the consumer was a more important driver. Costs that come with tracing products through (parts of) the supply chain were also found to not be a main driver in any of the four cases, except for relating traceability to detection technology to validate the origin of a food product; this was considered to be too costly in one of the four use cases.

The main challenges for improving traceability with blockchain technology were adoption, granularity, confidentiality, data governance, and data validation. Validation of data that will be stored in a blockchain solution is an issue, because food marked as organic or fair trade could still be noncompliant. For example, data of food that has been treated with pesticides could technically be entered, or farmers could be forced to say that their payment was fair. One of the use cases tried to ensure validation by having farmers confirm the trustworthiness of the transaction by SMS. Scalability, the labor-intensive character of storing data in an additional ledger (blockchain), privacy, and the process of data selection were also challenges. The ability to verify organic or fair-trade certification

TABLE 6 | Technical case information.

\begin{tabular}{lllll}
\hline & $\begin{array}{l}\text { No. } \mathbf{1} \text { Fairfood "Back to } \\
\text { the origin" }\end{array}$ & No. $\mathbf{2}$ FishTales Pole-caught tuna & No. $\mathbf{3}$ Anonymous & No. $\mathbf{4}$ Anonymous \\
\hline Ledger type & Public & Public & Private & Public \\
Authorization type & Permissioned & Not applicable & Permissioned & Permissioned \\
Implementation type & Open source & Not applicable & Proprietary & Proprietary \\
Tracking/verification type & QR code & QR code (not implemented) & QR code (consumer) & Label \\
Traceability data example & Available, origin product & Available, origin data used (but project & Not available & Not applicable (certification \\
& data used & ended in conceptual phase) & & reference stored)
\end{tabular}


data, establishing accountability in the supply chain, improving risk management, insights into trade transactions, simplified data collection and exchange, and improved communication were the main benefits.

From a technical point of view, both public and private blockchain solutions and open source and proprietary solutions were part of the study. Table 6 shows an overview of the technical aspects of the four cases.

An important technical element impacting whole-chain traceability is the way in which consumers and possibly other stakeholders are enabled to verify the origin of the product. A QR code is a two-dimensional barcode with a larger data capacity than a one-dimensional code, such as a barcode (Qian et al., 2017). It can be scanned to retrieve additional information or be directed to a website with more information, for example, about the product origin. A single QR coded tag is cheaper than an RFID tag. QR codes were used to improve customer transparency for Cases 1 and 3, both projects that are at the time of the writing of this article. During the interview for Case 3, it was stated that if a QR code could be printed “in line," in the production line

TABLE 7 | Organic traceability improvements with blockchain (case study).

\begin{tabular}{lcccc}
\hline Organic food traceability issue & Case 1 & Case 2 & Case 3 & Case 4 \\
\hline No EU organic data requirements & $\checkmark$ & $\checkmark$ & & \\
Certification fraud & $\checkmark$ & $\checkmark$ & $\checkmark$ & $\checkmark$ \\
Certification/chain transparency & $\checkmark$ & $\checkmark$ & $\checkmark$ & $\checkmark$ \\
Whole-chain traceability & $\checkmark$ & $\checkmark$ &
\end{tabular}

itself like it is applied for meat production, traceability would be made easier. However, for fruit and poultry production lines (eggs), this is too costly.

\section{Organic Traceability}

To understand the impact on traceability in the European organic food supply chain, the organic traceability issues from Organic Food Traceability: Types and Issues were also used to analyze the use cases (Table 7).

First, because blockchain stores transactional information and EU law has no requirements for organic data elements, it was investigated which data elements qualify for traceability improvements. The case study was able to retrieve examples of data elements for three cases of which Cases 1 and 2 actually stored certification data elements in the blockchain, instead of only a reference to the certificate. For all four cases, no specific data elements about pesticides usage were stored in the blockchain solution, because they were inherent to the certification itself.

The second issue of dependency on information gathered by certification bodies was alleviated by all blockchain projects. Instead of TPC inspecting farmers or farmer association's documents, the validation of origin information was performed at the earliest moment possible in the process (Case 2). Because Cases 1, 2, and 4 aimed at proving fair payment for farmers or fishermen, blockchain technology enabled confirmation of payments by traders at the source. For example, nutmeg farmers use an application on their mobile device and confirm each

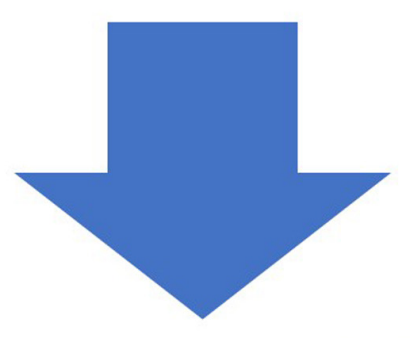

\section{Internal traceability}

Sharing logistic data and organic certification link in the Blockchain solution

\section{External traceability}

Sharing organic, origin and farmer data in the Blockchain solution
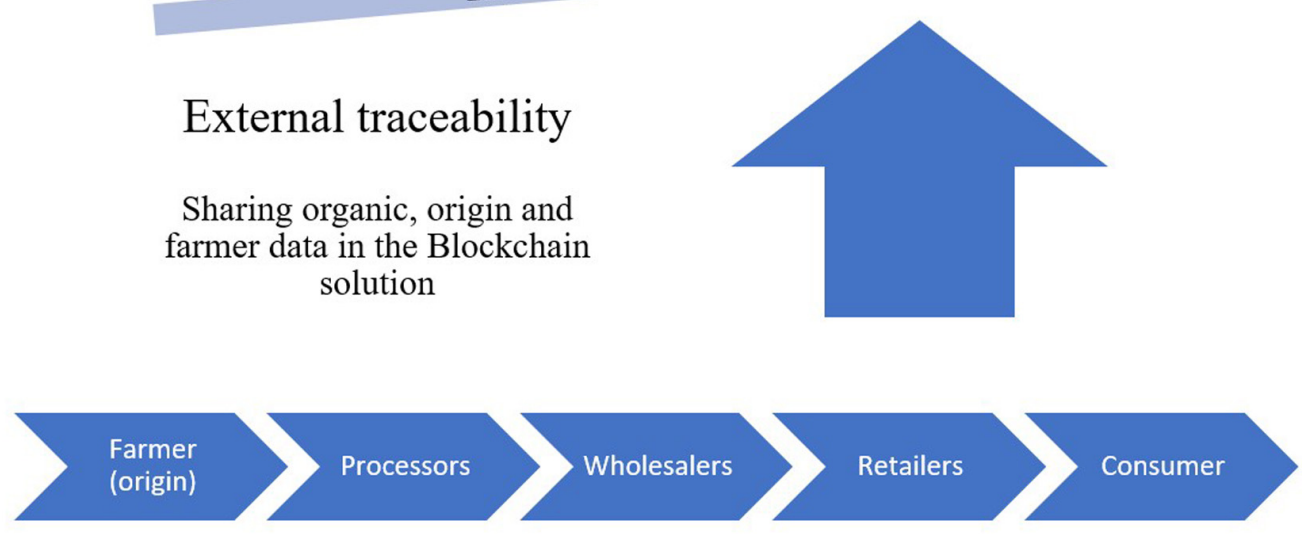

FIGURE 3 | Data sharing as the line of transparency for organic food information. 
transaction by confirming a text message. Subsequently, a fairtrade certifying process would in this case be superfluous and fraud in that sense would not occur. Another issue could, however, occur, because it is left undetermined if the information provided to the blockchain solution is validated.

Third, it was concluded that transparency is desired at the level of product ownership by chain partners, sharing transactional information and linking it to information about the origin of the product. Transparency was not always welcomed in the blockchain projects investigated. In all cases, confidentiality was an issue during the project. Several types of chain partners, farmers, traders, and importers initially hesitated to share information because of fear of losing competitive advantage; for example, the exact location of a farm could risk disclosing critical information about trading relations. This was resolved by using data currency ranges or location areas. Across the cases, it was also found that the selection of data to capture in the blockchain was quite dissimilar, from just a reference to a certificate to many data elements concerning the product origin and farmer information.

Whether whole-chain traceability is achieved by the projects depends on the degree of information sharing among chain partners. To different extents, chain partners already worked together with a certain amount of trust. Of those five partners, in Cases 1, 2, and 3, the earlier stages of the chain are handled by one "umbrella" organization, such as a company that buys from farmers and produces (locally). Because of this, it was found that initiating the project, deciding on information sharing and data interoperability was made easier. Furthermore, for Cases 1 and 2, the objective was to share information about the farmer or fisherman, whereas Cases 3 and 4 do not trace the products back beyond the farmers' cooperation, simply because of the scale of the citrus fruit and rice plantations.

\section{DISCUSSION}

This research evaluates the application of blockchain technology to improve organic or fair-trade food traceability from "Farm to Fork" in light of European regulations to overcome issues in the organic food industry. The empirical results of the four case studies showed that implementing blockchain can provide added value because of its characteristics of immutability, distributed ledger technology, and the ability to exchange data among chain partners. This has shown to create a form of pressure on the food supply chain. Driven by sustainability objectives like fair-trade or organically produced food, not being able or willing to share information through a blockchain solution may even lead to finding other suppliers that can meet these objectives. The "chain leads" who initiated the blockchain projects demonstrated accountability for the entire supply chain toward its consumers, although certification processes could be outsourced. Compliance to regulations and standards was regarded as the main responsibility of a wholesaler or retailer.
A blockchain solution may be built or customized to store any required data element. To adhere to the concepts from literature (Moe, 1998), this entails the selection of subdescriptors. By design, blockchain seems able to affect whole-chain traceability of organic food. Cases researched either selected a chain that was already well arranged, not too complex, or did not have more than five chain partners. This indicates that a supply chain was selected that was considered less complex. For three cases, chain operators already handled food through a separate production line. One case showed two value chains that qualified for blockchain technology (citrus fruit from South America and eggs within Europe). The alignment of renewing trade contracts with the shared focus on product traceability throughout the chain was an opportunity to improve collaboration in the chain in one of the cases.

These elements of chain optimization have led to faster blockchain implementations, because teaming up with chain partners can be more efficient between companies that have already (decided to) work together. It is important to recognize that traceability improvement projects can be technology-driven and identify issues in the supply chain around traceability as well as improve relationships between chain partners, even for discontinued projects. This also happened in the case of a small- to medium-sized fishery supply chain, which realized product transparency after ending the blockchain project by informing consumers about the product origin on their website and setting their own sustainable fishery standards.

Despite theoretical distinctions between various types of food traceability, internal traceability and external traceability were not used as such by the cases. An interaction line between internal and external traceability was uncovered in the selection of which data actually "gets into the blockchain," impacting the level of information transparency. This line is either pushed forward toward the consumer, sharing more information such as organic, origin, or farmer data, or pushed back toward the first chain partners, sharing less information with a focus on internal traceability such as logistics data (Figure 3). These considerations depend highly on the desired levels of confidentiality of chain partners and privacy of individuals, such as individual farmer data.

If more organic data are shared using blockchain, transparency in the organic food chain could lead to increased trust. The role of third-party intermediaries and TPC could move from inspecting each chain partner to validation of data that go into the blockchain. A simplified certification process could lead to less costs for all chain partners and stimulate organic trade or entry to the organic market.

\section{CONCLUSION}

Two of 4 cases have resulted in successful blockchain solutions that are operational to date. The successful projects in this use case study are the ones that are closest to meeting the criteria for organic food traceability. Cases 1 and 2 were most successful 
at creating whole-chain traceability, even though Case 2 did not use blockchain as a final solution. Although the project did not surpass the conceptual phase, because of adoption issues and difficulties interfacing with the current paper-based process, transparency to consumers was realized by publishing authorized origin information on the wholesaler website. In light of EU regulations and standards, the case study found that these are seen as important and especially strict in Europe, but as the responsibility of a wholesaler or retailer. GS1 was the standard that was best known to participants and knowledge of EU traceability law was limited.

The key explanation of how blockchain can improve food traceability in the organic food supply chain is the combination of "chain discovery" and "data capture" and for the supply chain leader to make the relevant choices depending on the characteristics of the organic chain.

Turning this statement around, does the organic food supply chain need blockchain in order to achieve wholechain traceability? The answer to that question is simply "No." Whether or not driven by technology, warnings from an NGO, a food incident, or the ambition to increase consumer satisfaction, improving whole-chain traceability can be done without blockchain technology. However, blockchain could certainly make food traceability faster and prove to be a good solution for a complex food supply chain.

Detection technology with sensors or sample testing to validate the origin of a food product was considered to be too costly. However, implementing these technologies in the organic food supply chain to validate food origin in the first steps of the chain could more accurately determine the origin of food than, for example, yearly sampling in a TPC process. If these technologies continue to develop into affordable applications, regulations and standards could facilitate the use of standard data elements to determine origin. Such a solution would have to capture and store organic data elements (about applied pesticides types and volumes and farmer payment, for example).

Blockchain lends itself for an organic food supply chain where certification bodies play a much smaller role or even no role at all. However, a (full) replacement of current certification processes is not expected to happen in the foreseeable future.

\section{Practical and Scientific Implications}

Based on this research, chain partners, certifying bodies, and farmers are advised to identify the drivers for organic food traceability improvement as part of their blockchain approach or, if supply chain improvements and chain collaboration have a higher priority, to start small: first "close the chain" and then start using technology. An important next step is determining the scope of the blockchain project, which can vary depending on the complexity of the supply chain, the blockchain type (public and private), and project type (proof of concept, prototype, Minimal Viable Product (MVP), and full solution). Also, selection of data elements or the descriptors and subdescriptors (Moe, 1998) that need to be captured at each step in the chain should be done carefully, and cautious reflection on the usage of farmer and consumer data should ensure General Data Protection Regulation (GDPR) compliance. When using incentives to facilitate technology adoption (higher prices for organic products with data, access to financing), farmer dependency on such new models should be researched first. Efforts of retailers to provide information about the product origin are exemplary, but consumers should become aware of the actual product value and origin information, after scanning a $\mathrm{QR}$ code and check if it concerns data coming from the source, as closely as possible.

This research addresses the intersection of food supply chain and organic food (quality and certification). Organic food supply chain concepts were researched regarding the traceability models from the literature (Kim et al., 1995; Moe, 1998; Bhatt et al., 2013; Aung and Chang, 2014). Interdisciplinary research to further improve the organic certification process and food traceability can apply the adapted model (Table 1). The focus on origin information and importance of organic data elements may underpin other research on EU regulations in relation to food traceability. The research adds value to the body of knowledge on the current status of blockchain technology, specifically in the organic and fair-trade food supply chain in light of EU regulations. It shows that blockchain is currently successfully being implemented on a small scale to obtain whole-chain traceability of organic and fair-trade food.

\section{Limitations}

This research has certain limitations. First, the selection of cases was tenaciously driven toward organic, and half of the cases handle organic food, but none of the blockchain projects actually stored data about pesticide usage or were able to provide information about the way detecting technologies could be a solution for increased validity of pesticide data (automatically) captured by a blockchain solution. Farm suppliers were not part of the selected projects.

Second, during the research, several findings about interoperability between blockchain solutions were found, but this was beyond the scope of this study. A third limitation is only cases from the Netherlands were part of the scope of this research, partly due to limited availability of information of commercial projects outside the Netherlands.

\section{Future Research}

Considering the organic food supply chain, the issues around traceability each deserve more research. Especially considering the complexity of current certification systems, it remains to be determined how even larger retail food supply chains that use blockchain technology, such as IBM Food Trust, are improving whole-chain traceability. Research on these complex food systems should broaden the research scope outside the Netherlands, and information about commercially driven platforms will need to be more accessible in order to do so. Adoption of blockchain technology is another research topic worth investigating, not just on the farmer side, but also how other chain partners 
and individual users take on the new ledger technology in their day-to-day practices in handling food traceability. The development of traceability standards and blockchain standards and how they relate are other subjects that are also interesting for future research.

\section{AUTHOR CONTRIBUTIONS}

All authors listed have made a substantial, direct and intellectual contribution to the work, and approved it for publication.

\section{REFERENCES}

Adolph, M., Narayan, A., Eskander, H., Mandahar, S., de Man, V., Ohlsson, B., et al. (2018). E-agriculture in action: Blockchain for agriculture, opportunities and challenges G. Sylvester, Ed. Food and Agriculture Organization of the United Nations: Rome

Atzori, M. (2015). Blockchain technology and decentralized governance: is the state still necessary? J. Govern. Regul. 6, 1-37. doi: 10.22495/jgr_v6_i1_p5

Aung, M. M., and Chang, Y. S. (2014). Traceability in a food supply chain: safety and quality perspectives. Food Control 39, 172-184. doi: 10.1016/j.foodcont. 2013.11.007

Back to the Origin (2019). Available online at: https://verstegen.fairfood.nl/trace/ (accessed on 30 December 2019).

Balakrishna Reddy, G., and Ratna Kumar, K. (2020). "Quality improvement in organic food supply chain using blockchain technology G," in Innovative Product Design and Intelligent Manufacturing Systems, Lecture Notes in Mechanical Engineering, eds B. Deepak, D. Parhi, and P. C. Jena (Cham: Springer), 887-896. doi: 10.1007/978-981-15-2696-1_86

Benbasat, I., Goldstein, D., and Mead, M. (1987). The case research strategy in studies of information systems. MIS Q. 11, 369-386. doi: 10.2307/248684

Bhatt, T., Buckley, G., McEntire, J. C., Lothian, P., Sterling, B., and Hickey, C. (2013). Making traceability work across the entire food supply chain. J. Food Sci. 78(Suppl. 2), B21-B27. doi: 10.1111/1750-3841.12278

Bhatt, T., and Zhang, J. J. (2013). Food product tracing technology capabilities and interoperability. J. Food Sci. 78(Suppl. 2), B28-B33. doi: 10.1111/1750-3841. 12299

Bitcoin Magazine. (2017). Innovation Percolates When Coffee Meets the Blockchain | Nasdaq. Available online at: https://www.nasdaq.com/articles/innovationpercolates-when-coffee-meets-blockchain-2017-04-17 (accessed on 23 December 2019).

Bolt, J., and Senou, O. (2019). Fairfood Hits the Ground Running With Blockchain. Available online at: https://www.cta.int/pt/blog/article/fairfoodhits-the-ground-running-with-blockchain-sid07cfad911-b780-4386-bbb0bff7afa05c46 (accessed on 10 May 2019).

Browne, A. W., Harris, P. J. C., Hofny-Collins, A. H., Pasiecznik, N., and Wallace, R. (2000). Organic production and ethical trade. Definaton, practice and links. Food Policy 25, 69-89. doi: 10.1016/S0306-9192(99)00075-5

Cai, Y., and Zhu, D. (2016). Fraud detections for online businesses: a perspective from blockchain technology. Finan. Innov. 2:20. doi: 10.1186/s40854-0160039-4

Casado-Vara, R., Prieto, J., La Prieta, F., De, and Corchado, J. M. (2018). How blockchain improves the supply chain: case study alimentary supply chain. Proc. Comp. Sci. 134, 393-398. doi: 10.1016/j.procs.2018.07.193

Charlebois, S., Sterling, B., Haratifar, S., and Naing, S. K. (2014). Comparison of global food traceability regulations and requirements. Comprehen. Rev. Food Sci. Food Saf. 13, 1104-1123. doi: 10.1111/1541-4337.12101

Cuéllar-Padilla, M., and Ganuza-Fernandez, E. (2018). We don't want to be officially certified! reasons and implications of the participatory guarantee systems. Sustainability 10, 1-15. doi: 10.3390/su10041142

Dobrovnik, M., Herold, D., Fürst, E., and Kummer, S. (2018). Blockchain for and in logistics: what to adopt and where to start. Logistics 2:18. doi: 10.3390/ logistics 2030018

\section{ACKNOWLEDGMENTS}

Gratitude goes out to those who represented the use cases and provided information openly.

\section{SUPPLEMENTARY MATERIAL}

The Supplementary Material for this article can be found online at: https://www.frontiersin.org/articles/10.3389/fbloc. 2020.567175/full\#supplementary-material

EFSA (2017). Pesticide Residues in Food: What's the Picture in the EU?. Parma: EFSA.

Eisenhardt, K. M. (1989). Building theories from case study research. Acad. Manag. Rev. 14, 532-550. doi: 10.2307/258557

Euractiv (2009). EU Report Reveals Pesticides in Organic Food. Parma: EFSA.

European Commission (2018). Directorate-General for Agriculture and Rural Development List of Control Bodies and Control Authorities in the Organic Sector. Available online at: http://ec.europa.eu/agriculture/ofis_public/pdf/ EUCBLIST_new1.pdf?uid=43D800FE-CE19-59A5-072726605DE566A7 (accessed May 24, 2019).

Fisheries-Fish Tales (2019). Available online at: https://www.fish-tales.com/en/ fisheries/ (accessed on 30 December 2019).

Galvez, J. F., Mejuto, J. C., and Simal-Gandara, J. (2018). Future challenges on the use of blockchain for food traceability analysis. TrAC Trends Anal. Chem. 107, 222-232. doi: 10.1016/J.TRAC.2018.08.011

Ge, L., Brewster, C., Spek, J., Smeenk, A., and Top, J. (2017). Blockchain for Agriculture and Food, Findings From the Pilot Study. Wageningen: Wageningen University \& Research.

Giannakas, K. (2002). Information asymmetries and consumption decisions in organic food product markets. Can. J. Agric. Econ. 50, 35-50. doi: 10.1111/j. 1744-7976.2002.tb00380.x

Hackius, N., and Petersen, M. (2017). "Blockchain in logistics and supply chain: trick or treat?", in Proceedings of the Hamburg International Conference of Logistics (HICL), Vol. 23, Hamburg.

Janssen, M., and Hamm, U. (2012). Product labelling in the market for organic food: consumer preferences and willingness-to-pay for different organic certification logos. Food Qual. Prefer. 25, 9-22. doi: 10.1016/j.foodqual.2011.12.004

Ji, G., and Tan, K. (2017). A big data decision-making mechanism for food supply chain. MATEC Web Conf. 100, 1-10. doi: 10.1051/matecconf/201710002048

Karthika, V., and Jaganathan, S. (2019). A quick synopsis of blockchain technology. Int. J. Blockchains Cryptocurr. 1:54. doi: 10.1504/ijbc.2019.101852

Kim, H. M., Fox, M. S., and Gruninger, M. (1995). “An ontology of quality for enterprise modelling," in Proceedings of the 4th IEEE Workshop on Enabling Technologies: Infrastructure for Collaborative Enterprises, (Berkeley: IEEE), 105116.

Kim, H. M., and Laskowski, M. (2018). Toward an ontology-driven blockchain design for supply-chain provenance. Intell. Syst. Account. Fin. Manag. 25, 18-27. doi: 10.1002/isaf.1424

Kraft, D. (2016). Difficulty control for blockchain-based consensus systems. Peerto-Peer Network. Appl. 9, 397-413. doi: 10.1007/s12083-015-0347-x

Kshetri, N. (2018). Blockchain's roles in meeting key supply chain management objectives. Int. J. Inform. Manag. 39, 80-89. doi: 10.1016/j.ijinfomgt.2017.12. 005

Langelaan, H., Pereira Da Silva, F., Thoden van Velzen, U., Broeze, J., Matser, A. M., Vollebregt, M., et al. (2013). Technology Options for Feeding 10 Billion People, Options for Sustainable Food Processing. Brussels: Science and Technology Options Assessment.

Lehtinen, U. (2017). "Sustainable supply chain management in agri-food chains: a competative factor for food exporters," in Sustainable Challenges in the Agrifood Sector, ed. R. Bhat, 150-174. doi: 10.1002/978111907 2737.ch7 
Lindvall, M., and Sandahl, K. (1996). Practical implications of traceability. Softw. Pract. Exp. 26, 1161-1180. doi: 10.1002/(SICI)1097-024X(199610)26:10<1161:: AID-SPE58<3.0.CO;2-X

Mainetti, L., Patrono, L., Stefanizzi, M. L., and Vergallo, R. (2013). An innovative and low-cost gapless traceability system of fresh vegetable products using RF technologies and EPCglobal standard. Comput. Electron. Agric. 98, 146-157. doi: 10.1016/j.compag.2013.07.015

Mendling, J., Weber, I., Van Der Aalst, W., Brocke, J. V., Cabanillas, C., Daniel, F., et al. (2018). Blockchains for business process management - challenges and opportunities. ACM Trans. Manag. Inform. Syst. 9, 1-16. doi: 10.1145/3183367

Mistry, I., Tanwar, S., Tyagi, S., and Kumar, N. (2020). Blockchain for 5Genabled IoT for industrial automation: a systematic review, solutions, and challenges. Mech. Syst. Signal Process. 135:106382. doi: 10.1016/j.ymssp.2019.10 6382

Moe, T. (1998). Perspectives on traceability in food manufacture. Trends Food Sci. Technol. 9, 211-214. doi: 10.1016/S0924-2244(98)00037-5

Munteanu, A.-R. (2015). The third party certification system for organic products. Netw. Intell. Stud. 3, 145-151.

Nakamoto, S. (2009). Bitcoin: A Peer-to-Peer Electronic Cash System. Available online at: https://bitcoin.org/bitcoin.pdf (accessed March 4, 2019).

Olsen, P., and Borit, M. (2018). The components of a food traceability system. Trends Food Sci. Technol. 77, 143-149. doi: 10.1016/j.tifs.2018.05. 004

Opara, L. U. (2003). Traceability in agriculture and food supply chain: a review of basic concepts, technological implications, and future prospects. Food Agric. Environ. 1, 101-106.

Qian, J., Du, X., Zhang, B., Fan, B., and Yang, X. (2017). Optimization of QR code readability in movement state using response surface methodology for implementing continuous chain traceability. Comput. Electron. Agric. 139, 56-64. doi: 10.1016/j.compag.2017.05.009

Rainforest Alliance (n.d.). Available online at: https://www.rainforest-alliance.org/ faqs/what-does-rainforest-alliance-certified-mean (accessed on 29 May 2020).

Schleenbecker, R., and Hamm, U. (2013). Consumers' perception of organic product characteristics. A review. Appetite 71, 420-429. doi: 10.1016/j.appet. 2013.08.020

Smit, B. (2002). Atlas.ti for qualitative data analysis: research paper. Perspect. Educ. $20,65-75$.

Swan, M. (2015). Blockchain: Blueprints for a New Economy. Sebastopol, CA: O’Reilly Media.
Underwood, S. (2016). Blockchain beyond bitcoin. Commun. ACM 59, 15-18. doi: $10.1145 / 2994581$

van Dijk, H. J. (2018). FishTales Presentation - Blockchain Event. Available online at: https://husite.nl/blockchainlab/wp-content/uploads/sites/227/2018/10/W2Harm-Jan-van-Dijk-compressed.pdf (accessed November 15, 2018).

Verhoog, H., Lammerts Van, Bueren, E. T., Matze, M., and Baars, T. (2007). The value of "naturalness" in organic agriculture. NJAS Wageningen J. Life Sci. 54, 333-345. doi: 10.1016/S1573-5214(07)80007-8

WEF (2015). Deep Shift: Technology Tipping Points and Societal Impact. Cologny: World Economic Forum.

WHO (2018). Pesticide Residues in Food. Geneva: WHO.

Wognum, P. M., Bremmers, H., Trienekens, J. H., Van Der Vorst, J. G. A. J., and Bloemhof, J. M. (2011). Systems for sustainability and transparency of food supply chains - Current status and challenges. Adv. Eng. Inform. 25, 65-76. doi: 10.1016/j.aei.2010.06. 001

Wolfert, S., Bogaardt, M., and Splinter, G. (2018). Towards Data-Driven Agri-Food Business. Available online at: https://www.slideshare.net/SjaakWolfert/towardsdatadriven-agrifood-business (accessed November 28, 2019).

Yin, R. (2018). Case Study Research and Applications - Design and Methods. Thousand Oaks, CA: SAGE Publications.

Zhang, Q., Huang, T., Zhu, Y., and Qiu, M. (2013). A case study of sensor data collection and analysis in smart city: provenance in smart food supply chain. Int. J. Distrib. Sensor Netw. 9, 1-12.

Zhao, G., Liu, S., Lopez, C., Lu, H., Elgueta, S., Chen, H., et al. (2019). Blockchain technology in agri-food value chain management: a synthesis of applications, challenges and future research directions. Comput. Ind. 109, 83-99. doi: 10. 1016/j.compind.2019.04.002

Conflict of Interest: The authors declare that the research was conducted in the absence of any commercial or financial relationships that could be construed as a potential conflict of interest.

Copyright (c) 2020 van Hilten, Ongena and Ravesteijn. This is an open-access article distributed under the terms of the Creative Commons Attribution License (CC BY). The use, distribution or reproduction in other forums is permitted, provided the original author(s) and the copyright owner(s) are credited and that the original publication in this journal is cited, in accordance with accepted academic practice. No use, distribution or reproduction is permitted which does not comply with these terms. 